\title{
Internal structure of Antarctic krill Euphausia superba swarms based on acoustic observations
}

\author{
Manuel Barange ${ }^{1}$, Denzil G. M. Miller ${ }^{1}$, Ian Hampton ${ }^{1}$, Timothy T. Dunne ${ }^{2}$ \\ ${ }^{1}$ Sea Fisheries Research Institute, Private Bag X2, 8012 Rogge Bay, Republic of South Africa \\ ${ }^{2}$ Department of Statistical Sciences, University of Cape Town, Rondebosch 7700, Republic of South Africa
}

\begin{abstract}
Ping-by-ping acoustic data from more than 3000 Antarctic krill Euphausia superba aggregations were analyzed and patterns in density distribution within the swarms examined. It was observed that krill were neither randomly nor evenly distributed within the swarms, particularly in larger swarms (extending for more than about $35 \mathrm{~m}$ along track), where there was significant evidence of krill concentration in the centre. Linear trends in density across swarms were also common. In swarms of intermediate size ( 15 to $35 \mathrm{~m}$ along track), these linear effects were predominantly negative, perhaps indicating reaction of the swarms to the approaching ship. Significant linear effects were present in the larger swarms as well, but in these, positive gradients were as common as negative ones. The effects of beam width on estimates of swarm density and internal structure made by echosounder are examined, and a method of correcting for these effects described. It was found that if no beam width correction is applied, artefacts are introduced into the apparent density structures, while the mean swarm density can be underestimated by as much as $50 \%$
\end{abstract}

\section{INTRODUCTION}

Antarctic krill Euphausia superba aggregations are cohesive units, within which individual length, sex ratio, moulting condition and gut fullness are characteristic of a single aggregation, but may differ between neighbouring aggregations (Watkins et al. 1986, 1990 , O'Brien 1987, Hamner et al. 1989, Priddle et al. 1990). Therefore, it has been suggested that the single aggregation or 'swarm' (sensu Miller \& Hampton 1989a) rather than the individual animal is the fundamental unit of interaction between krill and its patchy environment (Priddle et al. 1990). Recent analyses, however, suggest that such interaction may be complicated by the formation and dispersion of aggregations at a variety of spatial and temporal scales (Murphy et al. 1988, Miller \& Hampton 1989b, Miller et al. 1993).

The internal organization and behaviour of krill in swarms are poorly understood, although evidence has been presented (O'Brien 1989) to suggest that the selective mechanisms determining internal structure of euphausiid aggregations are probably analogous to those of fish schools (cf. Partridge et al. 1980). Despite the cohesive nature of krill swarms, large density gra- dients have been shown to exist within individual swarms (Godlewska \& Klusek 1987). From laboratory observations, such differences have been attributed to variable behaviour patterns (Antezana \& Ray 1983, Price 1989) and to continuous changes in position of individual animals within the swarm (Antezana et al. 1982, Strand \& Hamner 1990).

These laboratory studies have unfortunately been based on a limited number of observations subject to artificial constraints (Price 1989, Strand \& Hamner 1990). In addition, the discrete and selective character of net sampling appears inadequate to resolve fully sampling problems associated with the variability between swarms in the field (Watkins et al. 1986, 1990). The extent of internal organization of krill swarms in the open ocean therefore remains uncertain. Understanding this organization as a characteristic feature of krill behaviour is essential to interpret the relationship between krill dynamics and the variability of its environment.

Echo returns from krill aggregations may provide some insight into the internal organization of swarms, since they allow variations in density and structure to be resolved at a scale of less than a meter. In this paper 
we analyze the intensity of sequential (ping-by-ping) echo returns from krill aggregations, in order to examine the distribution of density within krill swarms.

\section{MATERIAL AND METHODS}

Data collection. Acoustic data were collected from MV 'Agulhas' in an area of the southwest Indian Ocean $\left(60\right.$ to $70^{\circ} \mathrm{S}, 15$ to $30^{\circ} \mathrm{E}$ ) between 16 February and 10 March 1981, as part of the First International BIOMASS Experiment (FIBEX). Krill echoes received from a hydrophone-calibrated Simrad EKS $120 \mathrm{kHz}$ echosounder, transmitting 128 pings $\mathrm{min}^{-1}$, were stored on a custom-built $100 \mathrm{kHz}$ digital data logger (Hampton \& Glaum 1975) for subsequent integration and other analysis ashore. Only echoes exceeding a preset threshold were stored. The data were collected as part of a general study into krill abundance, distribution and swarm morphology described by Hampton (1985) and Miller \& Hampton (1989b). The higher resolution of the data-capture system employed in the present study allowed a more detailed investigation of within-swarm structure than was possible with the lower-resolution echo-integrator used by these authors.

Data processing. In the analysis, echoes from swarms were isolated by checking for a sequence of at least 3 sequential returns ('pings'). Similarly, a break of at least 3 in the ping number (i.e. 3 consecutive returns below threshold) marked the end of the swarm (approximately $7 \mathrm{~m}$ at typical ship's speed). For each ping isolated, the mean volume back-scattering strength (MVBS) between the integration limits was calculated from the mean squared echo voltage between these limits. The mean squared echo voltage for all pings recorded from a swarm gave the MVBS for the insonified volume containing the swarm. The MVBS values were converted to volume densities (in ind. $\mathrm{m}^{-3}$ ) through the target strength (TS) expression used at the Post-FIBEX Acoustic Workshop (Anon. 1986) viz.:

$$
T S=20 \log L-77.2,
$$

where $L$ is the total length of the animal in $\mathrm{cm}$, obtained from the mean length in identification hauls with an RMT-8 net (see Hampton 1985 for further details). Multiplication by the width of the integration channel gave the number of individuals per square meter of surface above the swarms (surface density). Note that there is currently considerable disagreement about krill target strength at $120 \mathrm{kHz}$ (e.g. Miller \& Hampton 1989a, Foote et al. 1990), with recent measurements (Foote et al. 1990, Hewitt \& Demer 1991) typically suggesting values some 7 to $10 \mathrm{~dB}$ lower than given by the above expression (see also p. 120 in SC-
CAMLR 1991). We have however chosen not to revise our density estimates, but rather to regard them as relative instead of absolute, which is acceptable in this context as it is the relative densities within swarms and not the absolute values that are our prime concern.

An important consideration in estimating the mean densities from the individual ping data is the finite beam width of the transducer. As the swarm enters and leaves the approximately conical beam it is incompletely insonified for a number of pings, which results in the peripheral pings underestimating the density by an amount which depends on the beam characteristics and the depth of the swarm. The effect also tends to obscure the effect of true differences in density at the edges, which is an important subject of our investigation. To overcome this problem, peripheral pings were discarded, using knowledge of the beam characteristics to determine the number to be discarded as a function of depth. It is important to determine this number as accurately as possible, as discarding too few pings fails to eliminate artefacts in the across-swarm density profile, while discarding too many leads to loss of information on edge effects. The correction, which uses the intensity of the first recorded ping relative to the peak intensity to estimate the effective beam width and hence determine the number of peripheral pings to be discarded, is described in Appendix 1.

The intercepted length of each swarm, which is proportional to its along-track width, was estimated from the pulse-repetition rate, the number of pings received from the swarm, and the ship's speed, which was usually about 10 knots. Swarm vertical height (thickness) was defined somewhat arbitrarily as the vertical limits between which $97 \%$ of the echo energy was concentrated. This algorithm was chosen in preference to the more conventional definition as the difference between the first and last non-zero samples, as the latter is very sensitive to echo elongation due to multi-path scattering (Hampton et al. 1979).

Statistical analysis. In order to examine the observed patterns of swarm internal structure statistically, polynomial models of order 2 were applied to the pingby-ping density data from swarms returning at least 3 pings after correction, allowing the extraction of an intercept term, a linear term and a quadratic term for each

Table 1. Basic ANOVA table constructed to test for the existence of internal structure of krill swarms

\begin{tabular}{lcc|}
\hline Source & $\mathrm{df}$ & SS \\
\hline Linear & 1 & SSL \\
Quadratic & 1 & SSQ \\
Residual & $p-3$ & SSR \\
Total & $p-1$ & SST \\
\hline
\end{tabular}


swarm. These terms are independent of each other. The analysis was conducted as follows: for a swarm of $p$ pings (after correction) the corresponding $p$ percentages of the total swarm content were calculated and a basic ANOVA table constructed (Table 1). The linear and quadratic coefficients were obtained and standardized by the appropriate factor associated with the swarm size $p$ (e.g. Winer 1977). The resulting standardized coefficients each have a theoretical variance equal to the theoretical error variance for that swarm. The signs of the linear and quadratic effects were preserved and their average standardized value used in a $t$-test for significant positive or negative quadratic and linear effects. The tests were first performed assuming that the theoretical error variances are equal for all swarms, and then that they are equal only within swarms of a specified size $p$. In the latter case, the standardized $t$-statistics for the linear and quadratic effects were adjusted by applying a scale factor $[\sqrt{(p-3) /(p-5)}]$ to equalise the variance in these statistics to unity, under the null hypothesis of zero quadratic effects.

\section{RESULTS}

The frequency distribution of the number of pings per swarm before and after applying the beam correction is presented in Fig. 1. Only 1475 (46.8\% of the total) swarms were insonified by at least 1 ping after applying the beam correction. Of these, just over 900 were insonified by at least 3 consecutive pings, required for fitting the polynomial models. The rejection of most of the small swarms implies that at the chosen survey speed (approximately 10 knots), the ping rate of about 2 pings $\mathrm{s}^{-1}$ was too slow to estimate the density of most of them.

The mean surface density above each swarm was calculated before $(D B C)$ and after $(D A C)$ the beam effect correction (Fig. 2). The relationship between these 2 variables can be expressed as,

$$
D A C=1.419 D B C+2.37 \quad\left(\mathrm{n}=1475, \mathrm{r}^{2}=0.89\right)
$$

Closer analysis of the density correction factor $(D A C / D B C)$, however, shows that the relative weight of the discarded pings in the average density estimates

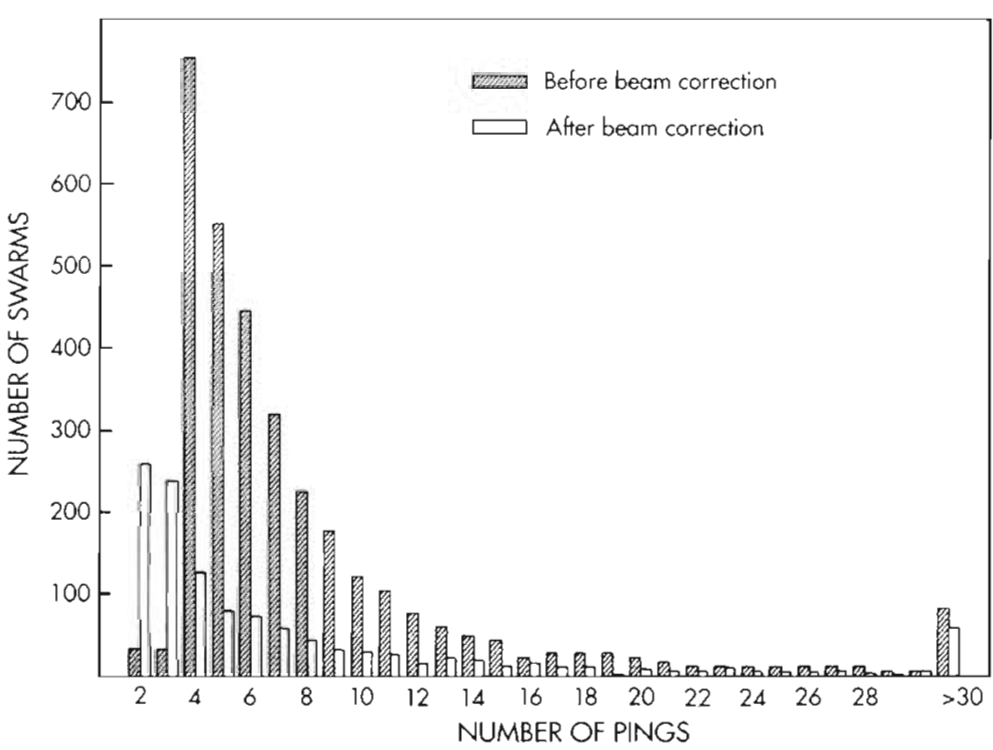

Fig. 1. Euphausia superba. Frequency distribution of the number of pings per swarm, before $(n=3154)$ and after $(n=1475)$ correction for transducer directivity

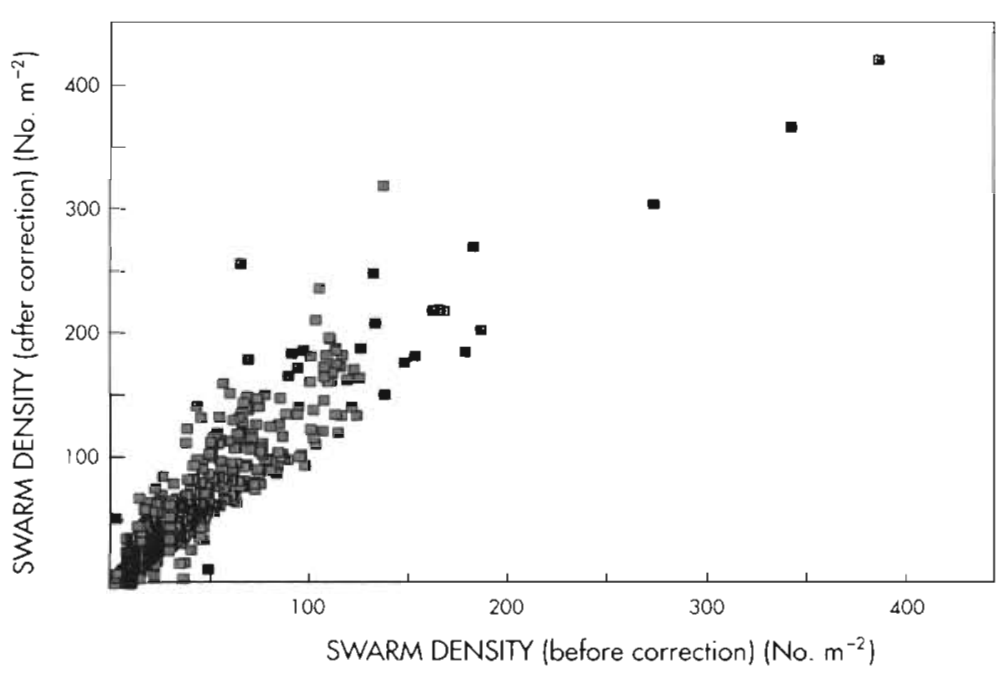

Fig. 2. Euphausia superba. Relationship between the average surface density above swarms before and after correction for transducer directivity

decreases as the size of the swarm increases (Fig. 3). Furthermore, it shows that this factor is markedly more variable for swarms insonified by fewer than approximately 20 pings, and extremely variable for swarms from which fewer than 5 pings were recorded.

All swarms were lumped together before and after correction to provide a comprehensive picture of the mean distribution of density along the intercepted swarm length. Average surface density was calculated separately for swarms with more and fewer than 20 


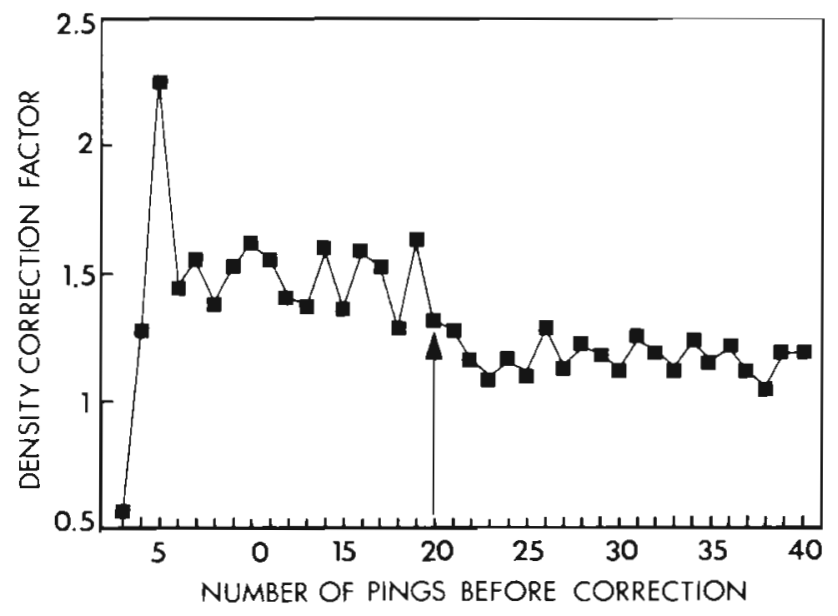

Fig. 3. Euphausia superba. Distribution of the density correction factor as a function of the number of pings per swarm before correction pings before correction, because of the markedly lower variability in the beam width correction above this limit (Fig. 3). These results are presented in Fig. 4. Note that 20 pings before correction gives on average 15 insonified pings after correction, equivalent to a distance of $35 \mathrm{~m}$ along track. The density distribution before correction strongly reflects the transducer directivity (Fig. 4a, b), with the first and last $20 \%$ of the pings indicating significantly lower densities than pings from the centre. After correction, the distribution of density along the intercepted length for small swarms (<20 pings; Fig. 4c) was different from that of large swarms (>20 pings; Fig. 4d). No general pattern in the density distribution was observed across small swarms, which could imply a random distribution of density along the intercepted length of the swarm, or alternatively, a mixture of effects of opposite polarity. For large swarms, however, there was a clear overall pattern of significantly higher surface density in the

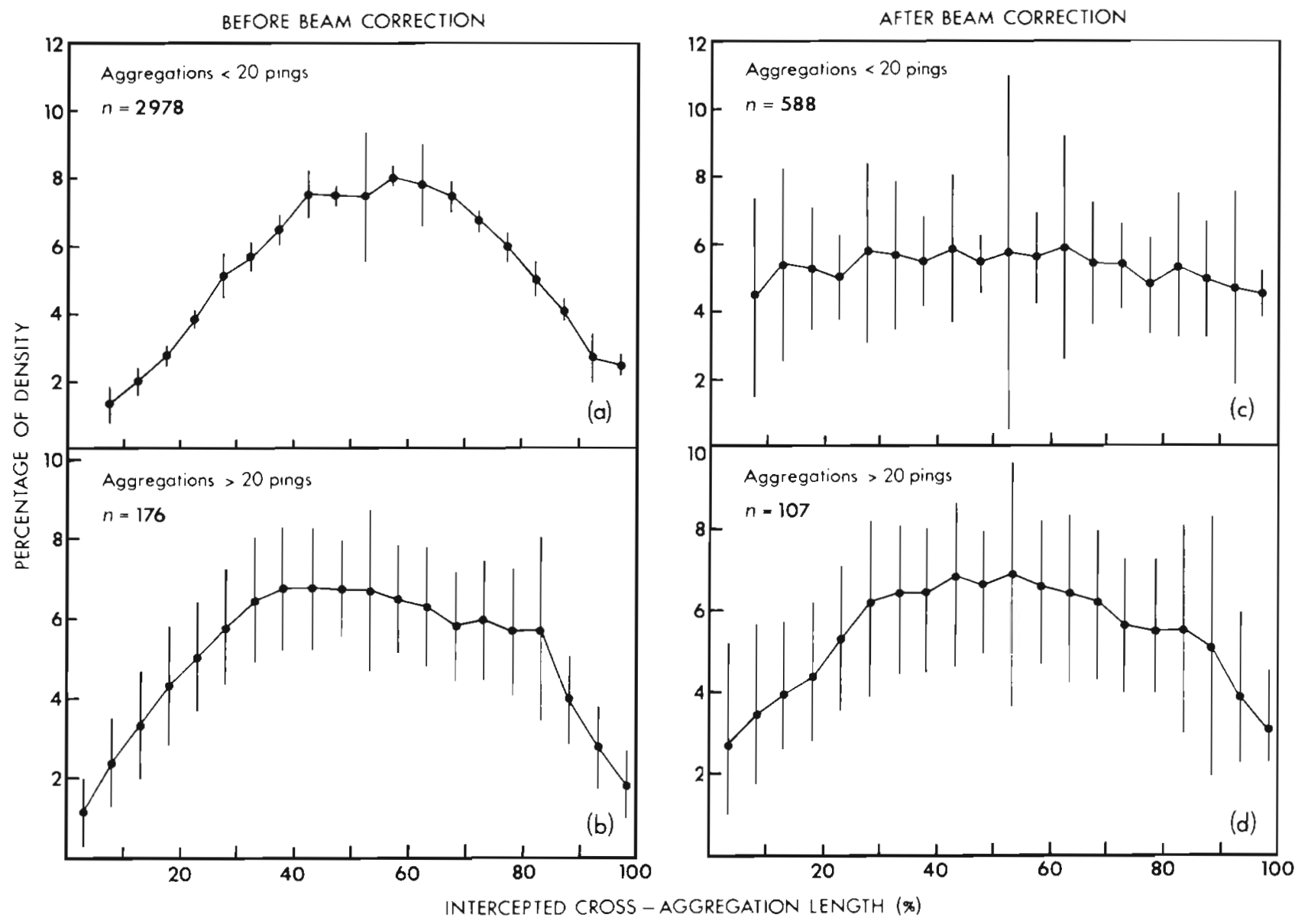

Fig. 4. Euphausia superba. Average distribution and standard deviation (vertical lines) of across-swarm density (as percentage of the total density). The intercepted length of all swarms was normalized as a percentage of the total length. Data are presented for swarms with more and fewer than 20 pings, before and after correction for transducer directivity, respectively. OnIy swarms bigger than 3 pings considered in (c) 


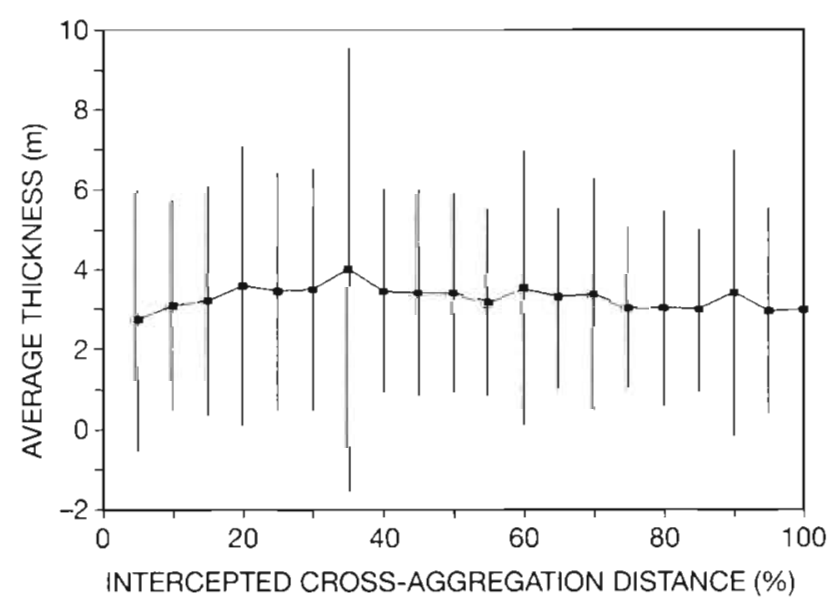

Fig. 5. Euphausia superba. Average distribution and standard deviation (vertical lines) of aggregation thickness (distance from top to bottom of aggregation). The intercepted length of all swarms was normalized as a percentage of the total length. Only swarms with more than 20 insonified pings considered

centre of the swarm, with decreasing density towards the edges. Since there was no trend in thickness across these swarms (Fig. 5), this also implies higher average volume densities (ind $\mathrm{m}^{-3}$ ) in the central region.

The fitting of the polynomial models to the data from individual swarms (described in 'Material and methods') enabled these patterns, or the apparent lack of them in the smaller swarms, to be examined in greater detail. In all 896 swarms were analyzed. Under the first assumption that the theoretical error variances

Table 2. Results of the ANOVA analyses performed to test the linear and quadratic effects and the individual $t$-statistics, and their changes between swarms of the same and different $p$ sizes. Values are number of swarms

\begin{tabular}{|c|c|c|c|c|}
\hline & & \multicolumn{3}{|c|}{ Swarm size } \\
\hline & & $\begin{array}{c}3-5 \\
\text { pings }\end{array}$ & $\begin{array}{c}6-14 \\
\text { pings }\end{array}$ & $\begin{array}{l}15-94 \\
\text { pings }\end{array}$ \\
\hline \multicolumn{5}{|c|}{ Quadratic effects } \\
\hline \multirow[t]{2}{*}{ Sign of $t$} & - & 223 & 150 & 125 \\
\hline & + & 203 & 154 & 41 \\
\hline \multirow[t]{4}{*}{ Value of $t$} & $t<-2$ & na & 24 & 71 \\
\hline & $-2<t<0$ & nà & 126 & 54 \\
\hline & $0<t<2$ & na & 132 & 22 \\
\hline & $t>2$ & na & 22 & 19 \\
\hline \multicolumn{5}{|c|}{ Linear effects } \\
\hline \multirow[t]{2}{*}{ Sign of $t$} & - & 203 & 213 & 82 \\
\hline & + & 223 & 92 & 84 \\
\hline \multirow[t]{4}{*}{ Value of $t$} & $t<-2$ & na & 139 & 51 \\
\hline & $-2<t<0$ & na & 74 & 31 \\
\hline & $0<t<2$ & na & 74 & 39 \\
\hline & $t>2$ & na & 18 & 45 \\
\hline
\end{tabular}

are equal for all swarms regardless of size, the linear and quadratic effects accounted for 40 and $38 \%$ of all the variation respectively. Although these percentages apply only to the absolute effects, since their signs are ignored in the analysis, they nonetheless suggest that important structural elements exist in the swarms. By preserving the signs of the quadratic effects, an average standardized quadratic coefficient of $-0.92( \pm 0.23)$ was obtained, which is significantly different from zero ( $\left.\mathrm{p}<1 \times 10^{-6}\right)$. It is thus concluded that in general the internal structure of swarms is non-random, with some higher density towards the centre. The same result was obtained from the second analysis, which did not assume common variance across all the swarms, but only within those of the same size. The average adjusted $t$-statistic (see 'Material and methods') obtained from this analysis gave an approximate $z$-statistic of $-5.86\left(\mathrm{p}<1 \times 10^{-6}\right)$, again confirming an average negative quadratic effect.

The frequency of linear and quadratic effects, and the standardized $t$-statistic for these effects in individual swarms, are also of interest. The results are shown in Table 2 for swarms in 3 different size groups. When, for a particular effect, markedly more than $5 \%$ of the swarms are observed to have an absolute $t$-value in excess of 2.0 , it can be inferred that the effect was significant, and that there was some systematic cause for it. Table 2 accordingly shows that the bulk of the evidence for the existence of negative quadratic effects comes from large ( $>15$ ping, i.e. longer than $35 \mathrm{~m}$ along track) swarms, in support of the evidence in Figs. $3 \& 4$ The $t$-statistics in Table 2 also show significant linear effects. In the large swarms, positive and negative effects are equally common, but in the swarms of intermediate size there is a preponderance of negative linear effects. Since the swarms were intersected randomly, systematic linear trends in density across them would be as likely to give rise to positive as negative linear profiles. We therefore infer that the observed asymmetry in the within-swarm density patterns is evidence of some systematic reaction of the medium-sized swarms to the ship.

\section{DISCUSSION}

Krill aggregations are relatively compact units, typically twenty to a few hundred meters across, that result from physical forcing as well as biological interactions (Miller \& Hampton 1989a). At the individual and swarm scale, turbulent diffusion and social behaviour undoubtedly play a major role in generating and maintaining these units (cf. Murphy et al. 1988, Miller \& Hampton 1989a). However, as already stressed, very little is known about the mechanisms and functioning 
of this apparent sociality (O'Brien 1989). Some observations have suggested that individual krill interact with each other to maintain and benefit from their gregarious behaviour. O'Brien (1989) concluded that crustacean aggregations (including krill) as a whole are non-optimally packed, and that individuals are not positioned at random with respect to their neighbours, suggesting that the internal structure of swarms is a consequence of behaviourally induced mechanisms. Hamner (1984) has observed that krill aggregations are usually narrower in one dimension than in the other, which allows individuals to exercise some control over the swarm edges, and reduces the distance to open water in at least one direction. Additional evidence of internal swarm organization has also been provided by Strand \& Hamner (1990). Our analysis of the density distribution within swarms has provided further evidence of internal organization within krill aggregations.

Several authors have assumed that krill are evenly distributed within swarms, while others have observed that the density across a swarm can vary by some orders of magnitude (Godlewska \& Klusek 1987). Our results strongly suggest that, at least in larger swarms ( $>20$ pings $\equiv 35 \mathrm{~m}$ ) on average krill tend to concentrate at the centre of the swarms, as has been observed in isolated examples by other authors (e.g. see Fig. 12 in Daly \& Macaulay 1988). This does not necessarily mean that the distribution of density is identical in all aggregations. In fact, in our data set densities peaked at all points along the intercepts, but when averaged over a large number of swarms, a tendency for the density to peak at the centre did emerge (Table 2). This trend was apparent even though few of the swarms would have been intersected through their centres.

The across-swarm distribution of density suggests that, in the large swarms, individuals near the swarm edge are more loosely packed and therefore less connected to the swarm than more centrally situated individuals. This observation is consistent with those of O'Brien (1989), who showed that individual krill exhibit a preference for specific loci within a swarm, and thus suggests that swarm formation and maintenance are not solely the product of physically controlled processes. It has been suggested that individual krill move from aggregation centre to edge, and vice versa, in response to either feeding condition and behaviour (Antezana et al. 1982, Antezana \& Ray 1983, Price 1989), concentration of excretory products (Strand \& Hamner 1990) and/or predator pressure (Antezana \& Ray 1983). As an alternative explanation, we suggest that peripheral individuals could be loosely connected to the aggregation, as a result of processes aiming at joining or leaving the swarm. Unequivocal support for this hypothesis is, however, not yet available.
A number of possible explanations can be offered for the observed differences in internal structure in swarms of different size. The fact that there was a predominance of negative quadratic effects in the larger (>35 $\mathrm{m}$ along track) swarms, but not in the smaller ones, could be partly an artefact of sizedependent bias in the correction for beam directivity. For example, if the correction was consistently too large, some evidence for lower densities at the edges would have been lost. This loss would have been greater for the smaller swarms, introducing an apparent difference in density profiles across swarms of different size. Although there is no reason in principle to suspect that the swarms were over- rather than under-corrected, this possibility cannot be ruled out. Alternatively, it could be speculated that for the small swarms, the number of pings after correction was insufficient to characterise their internal density distribution.

On the other hand, the differences could reflect reality, suggesting that the internal structure of swarms does depend on size. Such dependence could arise through relationships between swarm size and behavioural activities within the swarm, such as foraging, feeding or mating, all of which could result in characteristically different internal structure. Alternatively, many of the smaller swarms may have been in the process of leaving or joining another swarm, giving them different characteristics to those of the larger swarms. If a minimum size is required for a swarm to act as a structural unit, the smaller and larger swarms could perhaps be regarded as different functional units. In this regard, we note that Ricketts et al. (1992) observed that most swarms are either cohesive forms with simple shape or irregular forms containing several swarms indistinctly bounded.

As previously mentioned, the predominance of negative linear effects in swarms of intermediate size (15 to $35 \mathrm{~m}$ along track) suggests systematic reaction of swarms to the passage of the ship. That there is no such predominance in the larger swarms may indicate that swarm size per se has a direct effect on the escape responses of the animals contained therein (cf. O'Brien 1989). Alternatively, there may be indirect effects arising from some relationship between swarm size and activity, or between swarm size and individual size, brought about by, say, differences in swimming speed (cf. Hamner 1984). All these possibilities require further investigation.

On a larger scale, environmental forcing would probably play a greater role than behavioural mechanisms in determining krill distribution (Hampton 1985 , Weber \& El-Sayed 1985, Weber et al. 1986, Miller et al. 1993; also see reviews in Murphy et al. 1988 and Miller \& Hampton 1989a). More observations are, however, 
needed to determine the relative importance of physical factors as against behavioural mechanisms in the generation and maintenance of aggregations. It would be especially important to ascertain whether observed seasonal and regional variations in swarm size and density (Miller \& Hampton 1989a), are accompanied by differences in internal swarm structure. Such information would be useful in developing a dynamic model to explain how krill aggregations are formed, maintained and dispersed, and to determine the benefits of this behaviour at both the individual and swarm level.
Our study shows that at speeds and ping rates similar to those we used (which are typical for krill surveys) acoustic estimates of swarm density, and hence swarm biomass, will be negatively biased unless corrected for beam width effects. In our case the bias was most severe for swarms less than about $35 \mathrm{~m}$ long along track. This is close to the mean along-track length of krill swarms elsewhere (Table 19 in Miller \& Hampton 1989a), suggesting that our findings are generally applicable. To reduce the bias, and enable internal density structure to be resolved adequately, the survey speed should be reduced and the ping rate increased.

\section{Appendix 1. Correction for transducer directivity}

As a swarm passes into the beam, it is only fully insonified once a distance $d$ has been traversed, given by

$$
d=2 R \tan \phi_{e}
$$

where $R$ is the range to the swarm and $\phi_{\mathrm{e}}$ the angle off-axis at which the swarm is first detected (i.e. the effective beam width). It is assumed that propagation is vertical. If the ping rate is $F$ and the ship's speed $v$, the number of pings which insonify the swarm incompletely, and which should therefore be discarded for density determination, is given by

$$
N=\frac{F d}{V}
$$

The problem is therefore to determine $\phi_{e}$. We have done so by comparing the ratio between the energy in the first ping recorded from the swarm to the maximum energy recorded from it ( $E_{1} / E_{\max }$ ) (which corresponds to full insonification), for a large number (181) of the larger swarms. Assuming that the first ping is recorded at an angle of $\phi_{e}$, this ratio should be approximately equal to the ratio of the transmitted energy outside $\phi_{e}$ to the total energy in the beam, halved to allow for the fact that the swarm is only insonified from one side. The ratio enables $\phi_{\mathrm{e}}$ to be estimated from the beam directivity function as follows.

For our circular transducer, the total acoustic energy passing through a spherical surface subtended by angle $\phi_{0}$ at range $R$ is given by

$$
E=2 \pi k R^{2}\left(1-\cos \phi_{0}\right) \overline{B^{2}\left(\phi_{0}\right)}
$$

where $\overline{B^{2}\left(\phi_{0}\right)}$ is the squared ratio of the beam intensity at angle $\phi$ to the intensity on the axis, averaged over $\phi_{0}$; and $k$ is an equipment constant. The ratio of the energy within $\phi_{\mathrm{e}}$ to the total energy in the beam $\left(\phi_{0}=\pi / 2\right)$ is therefore

$$
E_{\phi_{e}}=\frac{\left(1-\cos \phi_{e}\right) \overline{B^{2}\left(\phi_{e}\right)}}{\overline{B^{2}(\pi / 2)}}
$$

$\overline{B^{2}\left(\phi_{0}\right)}$ can be estimated from Lozow's (1981) approximate expression:

$$
\overline{B^{2}\left(\phi_{0}\right)} \approx \frac{1-\mathrm{e}^{-2\left[(\pi D / \lambda) \sin \left(\phi_{0} / 2\right)\right]^{2}}}{(\pi D / \lambda)^{2}\left(1-\cos \phi_{0}\right)},
$$

where $D$ is the diameter of the transducer; and $\lambda$ the acoustic wavelength. Substituting (7) into (6) gives

$$
E_{\phi_{e}} \approx 1-\mathrm{e}^{-2\left[(\pi D / \lambda) \sin \left(\phi_{i} / 2\right)\right]^{2}}
$$

since the exponent for $\phi_{0}=\pi / 2$ is $\ll 1$.

For our transducer, $D / \lambda$ was measured as 7.86 from data in Hampton et al. (1981). Halving $E_{\phi_{e^{\prime}}}$ for the reason previously given, gave the relationship between $\overline{\left(E_{1} / E_{\max }\right)}$ and $\phi_{\mathrm{e}}$ shown in Fig. A1.

$\overline{\left(E_{1} / E_{\max }\right)}$ was $10.09 \%$ for the swarms examined, giving an effective beam width of $4.05^{\circ}$. Although this value is only approximate, it is less arbitrary, and probably more correct, than the $-3 \mathrm{~dB}$ point of the beam $\left(5^{\circ}\right.$ in this case), which is customarily taken in sizing fish schools acoustically (e.g. MacLennan \& Simmonds 1992). 


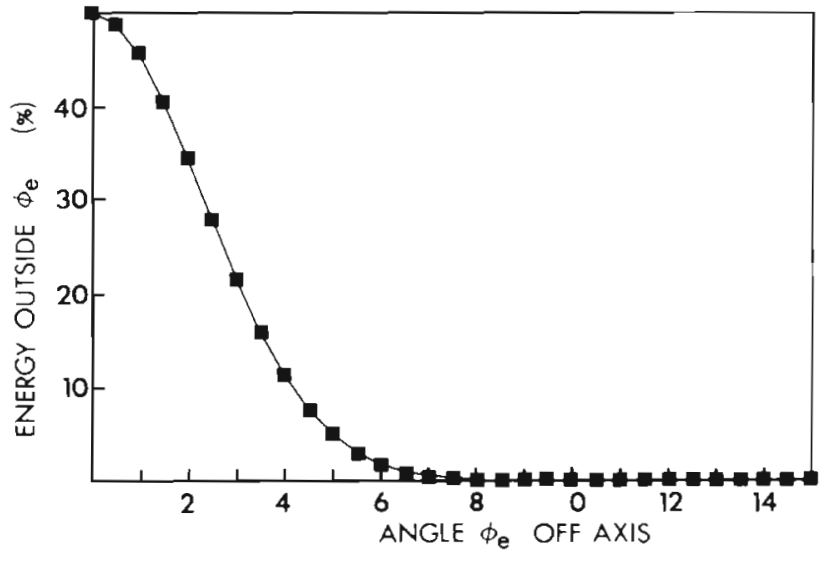

Fig. A1. Mean percentage of energy outside $\phi_{e^{\prime}}$ compared to total energy in beam, as a function of angle offaxis. Relationship is for a circular $120 \mathrm{kHz}$ transducer with a diameter of $10 \mathrm{~cm}$

Acknowledgements. The project was founded by the South African National Committee for Oceanographic Research (SANCOR), the South African Committee for Antarctic Research (SACAR) and the Sea Fisheries Research Institute. M.B. was supported by a post-doctoral fellowship from the Ministry of Education and Science of Spain (PF91/46115134). We thank J. Nelson and D. Merkle for their assistance in the data collection and analysis. Figures were partially prepared by Mr A. P. van Dalsen. Mr A. W. A. Murray (British Antarctic Survey) is acknowledged for his statistical suggestions which improved the final version of the manuscript substantially.

\section{LITERATURE CITED}

Anonymous (1986). Post-FIBEX acoustic workshop. BIOMASS Rep. Ser. 40

Antezana, T., Ray, K. (1983). Aggregation of Euphausia superba as an adaptive group strategy to the Antarctic ecosystem. Ber. Polarforsch. 4 (Sonderheft): 199-215

Antezana, T., Ray, K., Melo, C. (1982). Trophic behavior of Euphausia superba Dana in laboratory conditions. Polar Biol. 1: 77-82

Daly, K. L., Macaulay, M. C. (1988). Abundance and distribution of knll in the ice edge zone of the Weddell Sea, austral spring 1983. Deep Sea Res. 35: 21-41

Foote, K. G., Everson, I., Watkins, J. L., Bone, D. G. (1990) Target strengths of Antarctic krill (Euphausia superba) at $38 \mathrm{kHz}$ and $120 \mathrm{kHz}$. J. Acoust. Soc. Am. 87: 16-24

Godlewska, M., Klusek, Z. (1987). Vertical distribution and diurnal migrations of krill - Euphausia superba Dana from hydroacoustical observations, SIBEX, December 1983/January 1984. Polar Biol. 8: 17-22

Hamner, W. M. (1984). Aspects of schooling in Euphausia superba. J. crust. Biol. 4 (Spec. 1): $67-74$

Hamner, W. M., Hamner, P. P., Obst, B. S., Carleton, J. H. (1989). Field observations on the ontogeny of schooling of Euphausia superba furcilia and its relationship to ice in Antarctic waters. Limnol. Oceanogr. 34: 451-456
Hampton, I. (1985). Abundance, distribution and behaviour of Euphausia superba in the Southern Ocean between $15^{\circ}$ and $30^{\circ}$ E during FIBEX. In: Siegfried, W. R., Condy, P. R., Laws, R. M. (eds.) Antarctic nutrient cycles and food webs. Springer, Berlin, p. 294-303

Hampton, I., Agenbag, J. J., Cram, D. L. (1979). Feasibility of assessing the size of the South West African pilchard stock by combined aerial and acoustic measurements. Fish. Bull. S. Afr. 11: 10-22

Hampton, I., de Bruyn, P., Leonard, W. I. R., Paterson, M. J. (1981). Remotely controlled hydrophone system for calibration of hull-mounted echo-sounder transducers. Fish. Bull. S. Afr. 14: 115-121

Hampton, I., Glaum, F. G. (1975). A digital data logging system for acoustic studies of fish stocks. Proc. Conference on Instrumentation in Oceanography. Bangor, Wales, September 1975. Institute of Electronics and Radio Engineers, London, p. 193-202

Hewitt, R. P., Demer, D. A. (1991). Krill abundance. Nature 353: 310

Lozow, J. B. (1981). Transducer directivity: a simple calculation of its spatial values. In: Suomala, J. B. (ed.) Meeting on hydroacoustical methods for the estimation of marine fish populations, 25-29 June 1979. Il. Contributed papers, discussion and comments. The Charles Stark Draper Laboratory, Inc., Cambridge, MA, p. 495-524

MacLennan, D. N., Simmonds, E. J. (1992). Fisheries acoustics. Fish and Fisheries Series 5. Chapman and Hall, London

Miller, D. G. M., Barange, M., Klindt, H., Murray, A. W. A., Hampton, I., Siegel, V. (1993). Krill aggregation characteristics and structure from acoustic observations during FIBEX (First International Biomass Experiment). Mar. Biol. 112: in press

Miller, D. G. M., Hampton, I. (1989a). Biology and ecology of the Antarctic krill (Euphausia superba Dana): a review. BIOMASS Scient. Ser. 9

Miller, D. G. M., Hampton, I. (1989b). Krill aggregation characteristics: spatial distribution patterns from hydroacoustics observations. Polar Biol. 10: 125-134

Murphy, E. J., Morris, D. J., Watkins, J. L., Priddle, J. (1988) Scales of interaction between Antarctic krill and the environment. In: Sahrhage, D. (ed.) Antarctic ocean and resources variability. Springer, Berlin, p. 120-130

O'Brien, D. P. (1987). Direct observations of the behavior of Euphausia superba and Euphausia chrystallorophias (Crustacea: Euphausiacea) under pack ice during the Antarctic spring of 1985. J. crust. Biol. 7; 437-488

O'Brien, D. P. (1989). Analysis of the internal arrangement of individuals within crustacean aggregations (Euphausiacea, Mysidacea f. J. exp. mar. Biol. Ecol. 128: 1-30

Partridge, B. L., Pitcher, T., Cullen, J. M., Wilson, J. (1980). The three dimensional structure of fish schools. Behav. Ecol. Sociobiol. 6: 277-288

Price, H. J. (1989). Swimming behavior of krill in response to algal patches: a mesocosm study. Limnol. Oceanogr. 34: 649-659

Priddle, J., Watkins, J. L., Morris, D. J., Ricketts, C., Buchholz, F. (1990). Variation of feeding by krill in swarms. J. Plankton Res. 12: 1189-1205

Ricketts, C., Watkins, J. L., Priddle, J., Morris, D. J., Buchholz. F. (1992). An assessment of the biological and acoustic characteristics of swarms of Antarctic krill. Deep Sea Res. 39: $359-371$

SC-CAMLR (1991). Scientific Committee - Conservation of Antarctic Marine Living Resources. Report of the tenth meeting of the scientific Committee. Hobart, Australia, 21-25 October 1991. CCAMLR, Hobart 
Strand, S. W., Hamner, W. M. (1990). Schooling behavior of Antarctic krill (Euphausia superba) in laboratory aquaria: reactions to chemical and visual stimuli. Mar. Biol. 106: $355-359$

Watkins, J. L., Morris, D. J., Ricketts, C., Murray, A. W. A (1990). Sampling biological characteristics of krill: effect of heterogeneous nature of swarms. Mar Biol. 107: 409-415

Watkins, J. L., Morris, D. J., Ricketts, C., Priddle, J. (1986). Differences between swarms of Antarctic krill and some implications for sampling krill populations. Mar. Biol. 93: $137-146$

This article was submitted to the editor
Weber, L. H., El-Sayed, S. Z. (1985). Spatial variability of phytoplankton and the distribution and abundance of krill in the Indian Sector of the Southern Ocean. In: Siegfried, W. R., Condy, P. R., Laws, R. M. (eds.) Antarctic nutrient cycles and food webs. Springer, Berlin, p. 284-293

Weber, L. H., El-Sayed, S. Z., Hampton, I. (1986). The variance spectra of phytoplankton, krill and water temperature in the Antarctic ocean south of Africa. Deep Sea Res. 33: $1327-1343$

Winer, B. J. (1977) Statistical prunciples in experimental design. McGraw-Hill Kogakusha, Tokyo

Manuscript first received: May 29, 1992

Revised version accepted: June 25, 1993 